\title{
Aid groups back challenge to neem patents
}

London and New Delhi. An international coalition of more than 200 aid and environmentalist groups is backing a request to the US Patent and Trademarks Office (PTO) to withdraw a patent issued to the multinational company W. R. Grace on a method for extracting an active insecticide from the Indian neem tree.

The groups, which include several Indian organizations representing small farmers, are claiming that the patent is invalid because native knowledge of the tree, Azirdirachta Indica, whose extracts have been used for centuries not only to control insects but also for a range of medical purposes, should be regarded as 'prior art'.

Their request to the PTO follows a similar move in Europe at the beginning of June, organized by the Greens in the European Parliament. This challenges a patent issued earlier this year by the European Patent Office (EPO) jointly to Grace and the US Department of Agriculture (USDA) on a technique for using a chemical extract from the neem as a fungicide.

Both moves, which extend a campaign launched in India two years ago, are intended to focus attention on the way that the patent system permits multinational companies to lay claim to techniques based on the indigenous knowledge of Third World countries, if they are able to extend this knowledge using modern scientific methods.

Grace and other multinationals claim

that their only responsibility is to demonstrate to patent authorities that the specific techniques for which they are applying for a patent meet conventional criteria for novelty and inventiveness (the PTO has already granted over 50 patents on neem-based products from toothpaste to contraceptives).

The US patent under challenge, for example, refers to a technique Grace claims to be unique for extracting the chemical azadirachtin from neem tree seeds in a way that allows the extract to be stored for far longer than when it is Neem: patent battle ranges from India to America. extracted by traditional techniques.

Those seeking a re-examination of the US patent point out that long-term storage is in little demand in India, since the extract has traditionally been used soon after its preparation. But they claim to have evidence of several small Indian companies which have been engaged in developing storable neem extract, and the outcome of their challenge may depend on whether the practices of these companies will stand up in court as 'prior art'.

A spokesman for Grace, however, says that the patent concerned does not concern the processing of the extract, but only the unique formulation of its active ingredient, azadirachtin, without which the natural active ingredient degrades quickly. The company says that the claims against the patent, which have been filed in Washington

\section{Neem unsheaths contraceptive potential}

New Delhi. While the pesticidal quality of neem (azadirachta indica) is the main reason for the tree's attraction to multinational companies, scientists at the Defence Institute of Physiology and Allied Sciences (DIPAS) in New Delhi have filed a claim on a substance that they have isolated from neem oil which kills sperm on contact.

The substance DK-1, which the scientists hope to use as a vaginal contraceptive in the form of a cream or pessary, has been isolated from the volatile fraction code-named NIM-76 separated from neem oil. According to M. Selvamurti, DIPAS director, the substance is a potent germicide at a concentration of less than 0.2 per cent.

Pharmacological and acute toxicity trials on rats, rabbits and guinea pigs, carried out at the Central Drug Research Institute in Lucknow, have cleared DK-1 for phase-one human trials, due to begin in November. Selvamurti says these will be followed by a large-scale trial in 1996.

The institute has transferred the technology to two Indian drug companies who will scale-up production of the neem con- traceptive to produce the supplies needed during the phase-two trial and subsequent marketing. DIPAS scientists say that neem's historical role-as part of Indian folklore may make it more socially acceptable as a contraceptive than conventional birth control pills.

Tests have shown that DK-1 is stable at $45^{\circ} \mathrm{C}$. and has a shelf-life of at least six months. The neem isolate, says Selvamurti, has been subjected to the rigorous tests needed for pharmaceutical regulation. The contraceptive formulation will be licensed - unlike other herbal preparations, whose biological effects tend to show considerable variation.

Two more substances isolated from neem bitters also showed promise as potential contraceptives. But DIPAS intends to conduct trials only after it brings the first neem contraceptive onto the market. One of the substances, coded DNM-5, prevents implantation when administered orally in the early stages of pregnancy. The other fraction DNM-7 acts as an abortifacient. DIPAS has filed patent applications for all the three. by Jeremy Rifkin, director of the Foundation for Economic Trends, are "incorrect and without merit".

The neem issue is particularly sensitive because it has come to symbolize conflict between traditional and modern economic systems. Public protests against companies such as Grace delayed the passage through the Indian Parliament of new legislation on intellectual property designed to bring India's patent laws in line with those in the West as part of the outcome of the Uruguay round of the General Agreement on Tariffs and Trade.

Indian conservationists such as Vandana Shiva, director of the Research Foundation for Science, Technology and Natural Resources in Dehra Dun, one of the leading campaigners against the neem patent, hope that their campaign will draw world attention to the way that multinational corporations are patenting the biological resources of poorer nations.

"American people have only heard of software piracy," says Shiva. "What they don't know is that their companies are engaged in piracy of the worst kind in trying to profit from the traditional knowledge of India's farmers, who have been using neem as a pesticide for generations."

M. D. Nanjudaswami, head of the powerful Karnataka state farmers association, is confident that the patent will eventually be revoked. "If not, it would mean that indigenous populations around the world will not be able to freely use many of their local biological resources which they had developed and nurtured for centuries." Two years ago he led a widely publicized demonstration against a factory in Karnataka that supplies neem extracts to the US company.

One major concern to Indian farmers is the long term impact of the patent on the availability of neem seeds. With Grace already prepared to pay up to US $\$ 300$ per tonne of neem seeds, what used to be a free resource has now become a highly priced one. Shiva claims that a shortage of seeds will eventually force India's farmers to rely on Grace's product.

David Dickson and K. S. Jayaraman 